\title{
Maternal serum biochemical markers combined with ultrasound diagnosis at the end of the first trimester
}

\author{
MARIUS CRISTIAN MARINAȘ ${ }^{1}$, LUCIAN GEORGE ZORIL $\breve{a}^{2}$, CIPRIAN LAURENȚIU PĂTRU², \\ TIBERIU ȘTEFĂNIȚĂ ȚENEA COJAN ${ }^{3}$, VLAD DUMITRU BALEANU ${ }^{*}$, DRAGOŞ VIRGIL \\ DAVITOIU ${ }^{5}$, BOGDAN NICULESCU ${ }^{6}$, ANCA ROXANA PASCAL ${ }^{7}$, BOGDAN SOCEA ${ }^{8}$, EFREM ION \\ CRISTIAN', RĂZVAN GRIGORAȘ CĂPITĂNESCU² \\ ${ }^{1}$ Anatomy Department, University of Medicine and Pharmacy from Craiova, Department of Obstetrics and Gynecology, \\ Emergency County Hospital from Craiova, Romania \\ ${ }^{2}$ Obstetrics and Gynecology Department, University of Medicine and Pharmacy from Craiova, Emergency County Hospital \\ from Craiova, Romania \\ ${ }^{3}$ Department of General Surgery, University of Medicine and Pharmacy from Craiova, Romania \\ ${ }^{4}$ Surgery Department, Clinical Emergency Hospital Sf. Pantelimon, 340-342 Pantelimon Road, 021659, Bucharest, Romania \\ ${ }^{5}$ Carol Davila University of Medicine and Pharmacy of Bucharest, Surgery Department, Clinical Emergency Hospital \\ Sf. Pantelimon, Bucharest, Romania \\ ${ }^{6}$ University Constantin Brancusi of Targul Jiu, Department of Sports and Health, Targul Jiu, Gorj County, Romania \\ ${ }^{7}$ Department of Anesthesiology and Intensive Care, University Emergency Hospital Bucharest, Bucarest, Romania \\ ${ }^{8}$ Carol Davila University of Medicine and Pharmacy of Bucharest, Surgery Department, Clinical Emergency Hospital \\ Sf. Pantelimon, Bucharest, Romania \\ ${ }^{9}$ University of Medicine and Pharmacy, Faculty of Dental Medicine, Internal Medicine and Gastroenterology Department, \\ Municipal Hospital "Filantropia", Craiova, Romania
}

\begin{abstract}
Objectives. Evaluating the benefits of an early screening of combined maternal markers and ultrasound of the fetuses.

Methods. Prospective study (1 January and 31 December 2018) enrolled 187 patients, evaluated at the end of the first trimester of pregnancy (nuchal scan). Biochemical markers: detection of free $\beta$ human chorionic gonadotropin and serum pregnancy associated plasma protein A. The first trimester ultrasound examination included the assessment of the nuchal translucency, fetal crown rump length and fetal heart.

Results. 9 cases with abnormal biomarkers, increased nuchal translucency and cardiac anomalies, including abnormal 4 -chamber view ( 6 cases) and great vessel anomalies ( 3 cases). 1 case considered initially negative in the first trimester was diagnosed by morphological scan with tetralogy of Fallot in the second trimester.

Conclusions. A first trimester combined ultrasound protocol and maternal serum biochemical markers is important in the early prenatal care screening.
\end{abstract}

Keywords First-trimester ultrasound, cardiac abnormalities, maternal serum.

To cite this article: MARINAȘ MC, ZORILĂ LG, PĂTRU CL, COJAN TST, BALEANU VD, DAVIDOIU DV, NICULESCU B, PASCAL AR, SOCEA B, CRISTIAN EI, CĂPITANESCU RG. Maternal serum biochemical markers combined with ultrasound diagnosis at the end of the first trimester. Rom Biotechnol Lett. 2021; 26(4): 2879-2884. DOI: $10.25083 / \mathrm{rbl} / 26.4 / 2879-2884$ 


\section{Introduction}

A first trimester screening based on the analysis of biochemical markers in maternal serum has become partof the obstetric antenatal care. The correlated maternal biochemical markers are the free $\beta$ human chorionic gonadotrophin (free $\beta \mathrm{HCG}$ ) and pregnancy associated plasma protein-A (PAPP-A).

An accurate prenatal ultrasound diagnosis is also important because congenital heart diseases (CHD) are the most common anomalies, with an estimated incidence of 4-13 per 1000 live births (ALLAN et al, 1994 [1]).

Literature describes the importance of an early ultrasound detection of fetal heart abnormalities in high risk pregnancies associated with modified maternal serum biochemical markers and chromosomal abnormalities (BAHADO-SINGH et al, 2005 [2], TENEA-COJAN et al, 2012 [3]). Studies also demonstrate that ultrasound can be a useful tool in the diagnosis of major heart abnormalities in low risk pregnancies (BECKER et al, 2012 [4], PATRU et al, 2017 [5], VASILE et al, 2009 [6]), which must be reevaluated and confirmed at the second trimester morphological scan.

In most European countries a combined ultrasound and maternal serum biochemical markers screening has been established as part of the routine prenatal care. Evidence based medicine shows that the prenatal detection of fetal congenital and chromosomal anomalies as part of a screening program for the whole pregnant population is feasible and effective (BAHADO-SINGH et al, 2005 [2], PERSICO et al, 2011 [7], RADU et al, 2018 [8])

The maternal biochemical markers screening has limitations regarding the fetal neural tube defect detection because this would require either a second trimester separate alfa fetoprotein test or a detailed morphological scan between 19 to 24 weeks of gestation.

\section{Materials and Methods}

This is a prospective observational study that included 187 patients - unselected pregnancies - that were evaluated at the end of the first trimester during the nuchal scan using a Voluson 730 PRO-GE Healthcare Systems (Figure 1A). The patients were admitted in the Obstetrics and Gynecology Department of the Emergency County Hospital from Craiova between 1 January and 31 December 2018.

Gestational age ranged between 12 weeks +0 days and 13 weeks +6 days based on the fetal crown-rump length (CRL) measurement (Figure 1B). The patients were examined by transabdominal and transvaginal ultrasound in Grey-scale and color Doppler mode.

The first trimester ultrasound examination included the assessment of the nuchal translucency (Figure 1A), fetal crown rump length and evaluation of the fetal heart.

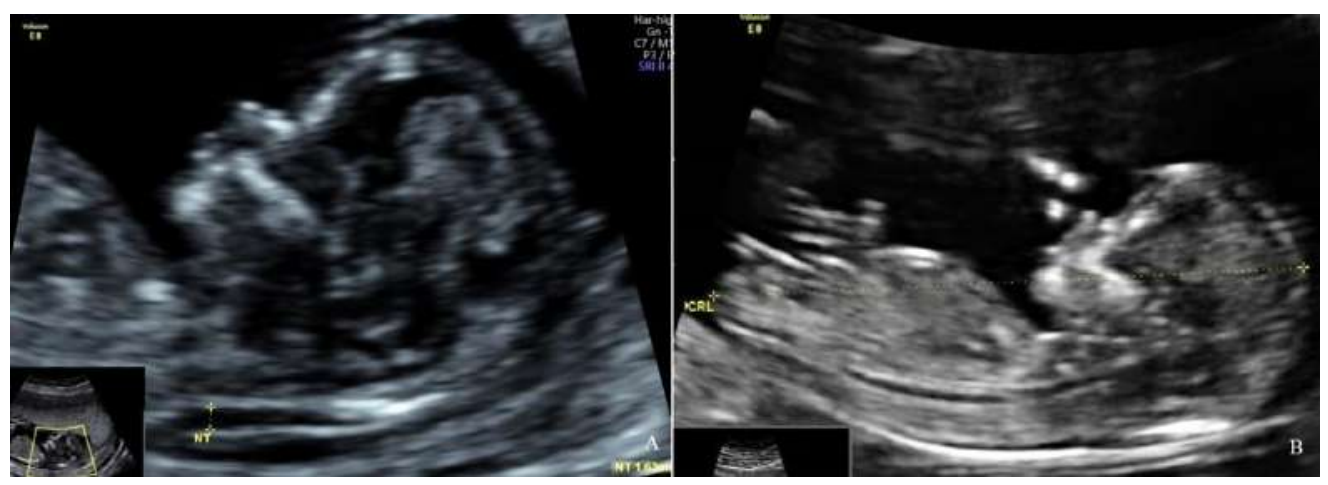

Figure 1. A. Nuchal translucency measurement; B. Crown-rump length measurement.

The fetal assessment included a demonstration of normal/abnormal fetal head, abdominal wall, diaphragm, stomach, limbs, umbilical cord insertion, kidneys, bladder and spine (Figure 2).

The fetal heart protocol included the four-chamber view and the outflow tract views. The evaluation started with the four-chamber view; this included the evaluation of the heart area (no more than one third of chest area), right- and left-sided structures approximately equal, the normal offset of the two atrio-ventricular valves. The left and right ventricular outflow tracts were evaluated in regards with their size (equal in size). The visualization of the crossing over was attempted in each case (Figure 3). A major heart anomaly was defined as a fetal heart defect that has the potential to be life-threatening and usually requires medical or surgical intervention after birth. 


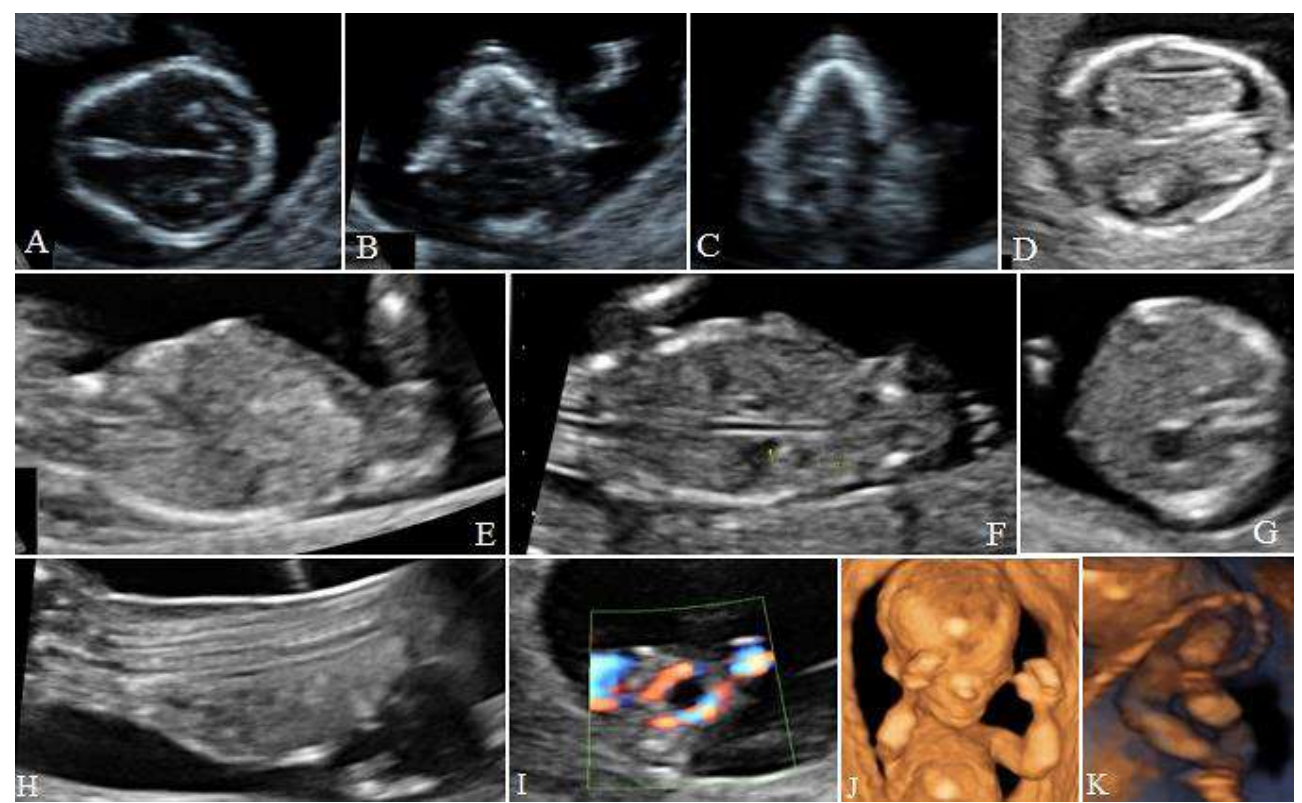

Figure 2. First trimester fetal morphology assessment. A, B, C and D. fetal head; E. diaphragm; F. kidneys; G. stomach; H. spine; I. bladder and umbilical cord; J and K. fetal limbs.

The maternal serum biochemical markers included the detection of the free $\beta$ human chorionic gonadotropin and serum pregnancy associated plasma protein $\mathrm{A}$. The biochemical markers were obtained either between 9-10 weeks of gestation or at the time of the nuchal scan.

After the late first trimester ultrasound, a follow-up scan was performed. This included the evaluation of the fetal morphology in the second trimester between 19-24 weeks of gestation.

In our case series, after the second trimester confirmation of the fetal abnormalities the couples were extensively counseled. When major structural abnor- malities were confirmed, the couples required medical termination of pregnancy.

In these cases, the antenatal diagnosis was compared with the pathological examination. In the rest of the cases, the fetuses were followed up until delivery and the antenatal diagnosis was compared with the postnatal examination.

The postnatal assessment was made by a multidisciplinary team including an obstetrician, neonatologist, cardiologist and pediatric surgeon.

The cases that required surgical intervention were referenced to specialized neonatal cardiac centers.

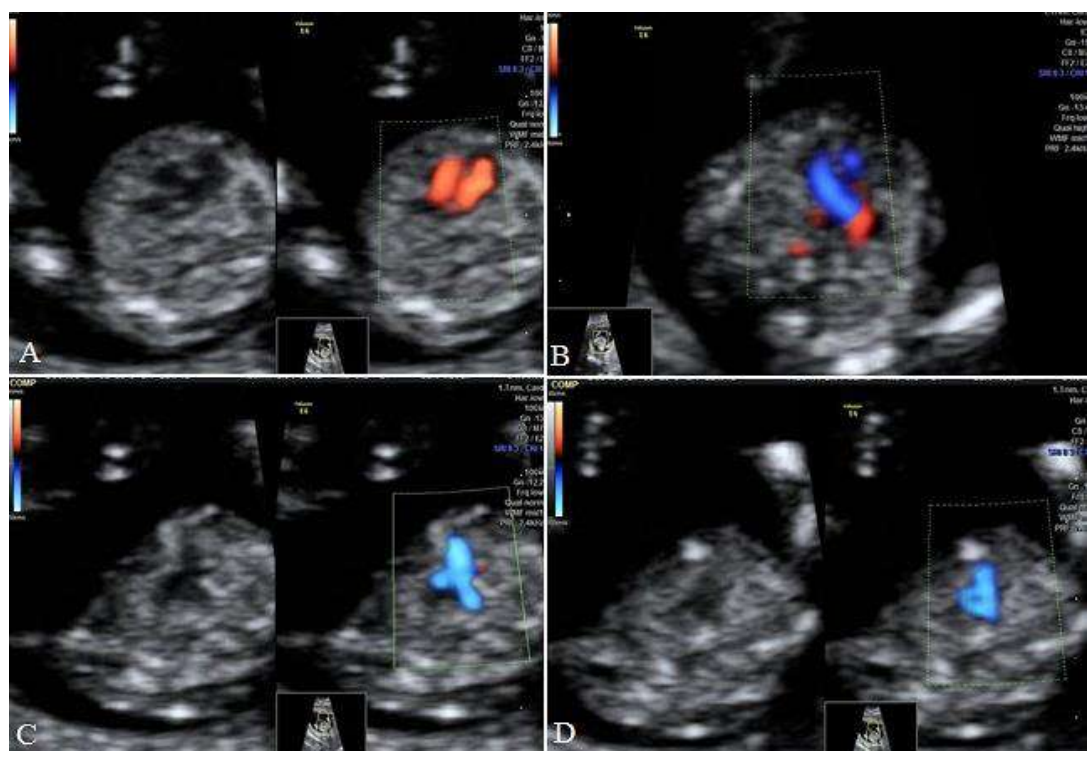

Figure 3. Four-chamber view: A. 2D Gray scale (on the right side) and Color Doppler mode (on the left side) demonstrates the left and right atrio-ventricular flows. Outflow tract view: B. Color Doppler mode demonstrates the emergence of left outflow tract; C. Color Doppler mode demonstrates the emergence of right outflow tract; D. Three vessels and trachea view: color Doppler mode demonstrates the confluence of the two arterial arches on the left side of the spine. 


\section{Results}

The study enrolled 187 unselected patients. The gestational age ranged between 12 weeks +0 days and 13 weeks +6 days based on the fetal crown-rump length measurement. The mean gestational age at diagnosis was 12 weeks and 2 days and the mean maternal age was 28 years.

During the study period, 9 cases with abnormal maternal serum biomarkers, increased nuchal translucency and cardiac anomalies were diagnosedin the first trimester.

Decreased levels of PAPP-A before the 14th week of gestation were associated with an increased risk for Down syndrome and trisomy 18, and increased levels of hCG were associated with an increased risk of Down syndrome.

Using the four-chamber view plane, we diagnosed 3 cases of complete atrio-ventricular septal defect, 1 case of hypoplastic left heart syndrome and 2 cases of hypoplastic right heart syndrome.

The outflow tract view diagnosed 3 cases with abnormal great vessels: 1 case of aortic coarctation and 2 cases of Tetralogy of Fallot. 1 case which was initially considered negative in the first trimester was diagnosed with Tetralogy of Fallot in the second trimester during the morphological scan.

The four-chamber view plane was obtained in $91 \%$ of the fetuses when the gestational age ranged between 12 weeks +0 days and 12 weeks +6 days, increasing to $98 \%$ when the gestational age ranged between 13 weeks +0 days to $13+6$ weeks. The outflow tracts plane was obtained in $87.1 \%$ of the fetuses and $99 \%$ after using the transvaginal technique.

From all the 9 pathologic cases, 2 cases were diagnosed with chromosomal abnormalitiesbecause of modified maternal serum biomarkers and associated major heart defects. One case was diagnosed with Trisomy 18 and associated atrio-ventricular septal defect and the other case was diagnosed with Trisomy 13 and associated hypoplastic left heart. Both cases had normal nuchal translucency at the first trimester scan.

In all cases diagnosed with major heart defects the couples decided to terminate the pregnancy. The pathological examination confirmed the antenatal diagnosis.

\section{Discussion}

Maternal Serum PAPP-A is a glycoprotein with molecular weight of $400 \mathrm{kDa}$, produced by the placental syncytiotrophoblast and deciduas. It increases the bioavailability of insulin like growth factor, which in turn mediate trophoblast invasion and modulates glucose and amino acids transport in the placenta. In normal pregnancy, the maternal serum concentration of PAPP-A increases with gestational age. Its concentration increases exponentially with a doubling time of 3-4 days during the first trimester, then the level continues to rise throughout pregnancy until delivery.
Decreased levels of PAPP-A are associated with abnormal placental function. Low first trimester maternal biochemical levels are found in trisomy 21, trisomy 18 and trisomy 13 but also in others fetal aneuploidies. A strong relationship between PAPP-A and fetal birth weight was detected (PERSICO et al, 2011 [7]), as PAPP-A decreases, the risk of small-for-gestational-age fetuses increases.

Human chorionic gonadotropin is a glycoprotein hormone with molecular weight of $39.5 \mathrm{kDa}$ composed by two subunits alpha and beta joined noncovalently, normally found in maternal serum and urine only during pregnancy, mediating multiple placental, uterine and fetal functions including development of syncytiotrophoblast cells, mitotic growth and differentiation of the endometrium (FONG et al, 2004 [9]).

Maternal serum hCG peaks at 8-10 weeks of gestation and declines to reach a plateau between $18-20$ weeks of gestation.

The new technology for biochemical analysis combines biochemical and ultrasound markers which provides accurate and reproductive measurements for an early assessment.

In the maternal serum biochemical markers screening, the results are converted into MoM (multiple of median) of unaffected pregnancies at the same gestation age. MoM values are calculated by dividing an individual's marker level by the median level of that marker for the entire population at that gestational age. Using MoM values, rather than absolute levels, allows results from different laboratories to be interpreted in a consistent way.

The development of high-resolution ultrasound machines permits a better evaluation of the fetal heart in the first trimester (PERSICO et al, 2011 [7], (FONG et al, 2004 [9]). In our opinion, the fetal heart must be assessed as early as possible during pregnancy because the congenital heart diseases are the most common congenital abnormalities and most cases occur in the low-risk population (HAAK et al, 2002 [10], VÎLCEA et al, 2008 [11], LI et al, 2013 [12]). Using an appropriate protocol, most fetal heart defects can be diagnosed at the end of the first trimester. To increase the detection rate, we suggest that a combined examination protocol that includes the nuchal translucency measurement, the four-chamber and outflow tract views and maternal serum biomarkers should be used.

The four-chamber view and the outflow tract view are two important planes for the fetal heart assessment. The four-chamber plane assesses the size and structure of the cardiac chambers and the outflow tract view gives information about the emergence, shape, diameter and relationship of the great vessels. The ultrasound assessment of the two plane scan increase the diagnosis of the congenital heart disease (OGGE et al, 2006 [13]).

A second trimester ultrasound follow-up is required as many defects can be missed at the FT scan (small atrial/ventricular septal defects) or may evolve (Tetralogy of Fallot, aortic coarctation) (SMRCEK et al, 2006 [14], TENEA COJAN et al, 2018 [15]) 
The association between congenital heart defects and chromosomal abnormalities was demonstrated (MULLER et al, 2007 [16], TENEA COJAN et al, 2018 [17], CLUR et al, 2009 [18]). This is important because most patients are scanned at the end of the first trimester as part of the nuchal translucency screening process and this may help the congenital heart defects diagnosis (BELLOTTI et al, 2010 [19], MAKRYDIMAS et al, 2005 [20]).

On the other side, a correct antenatal diagnosis of the fetal heart defects may lead to the diagnosis of chromosomal anomalies even in cases with normal nuchal translucency (BECKER et al, 2006 [21], ENE et al, 2016 [22], SALTVEDT et al, 2006 [23]). We detected one case of Trisomy 18 and one case of Trisomy 13 with normal NT because of the associated major heart defects (NEDELCUTA et al, 2017 [24], NEDELCUTA et al, 2019 [25], STANESCU et al, 2015 [26]).

A first trimester detection of major fetal structural abnormalities, especially heart defects is important for the couples counseling, pregnancy follow-up and postpartum management (CLENCIU et al, 2019 [27], NEDELCUTA et al, 2019 [28], GHEORMAN et al, 2019 [29]). This offers the couples a correct decision for the ongoing pregnancy (CARVALHO et al, 2004 [30]) and the decision of an early termination (RASIAH et al, 2006 [31]).

\section{Conclusions}

At the end of the first trimester, a fetal structural assessment is feasible. In our opinion, a first trimester detailed fetal heart protocol that includes the four-chamber view and the out-flow tract view assessment should be included in the prenatal ultrasound screening to improve the early fetal heart defects detection rate, pregnancy management and postpartum follow-up. Because cardiac defects may be part of an evolving disease and occur later during pregnancy, a second trimester cardiac examination should be considered.

\section{Acknowledgement}

All authors contributed equally.

\section{Conflict of Interest}

The authors declare no conflict of interest.

\section{References}

1. ALLAN LD, SHARLAND GK, MiLBURN A, LOCKHART SM et al. Prospective diagnosis of 1006 consecutive cases of congenital heart disease in the fetus. J Am Coll Cardiol. 1994; 23(2): 1452-1458.

2. BAHADO-SINGH RO, WAPNER R, THOM E, ZACHARY $\mathrm{J}$ et al. Elevated first-trimester nuchal translucency increases the risk of congenital heart defects. First Trimester Maternal Serum Biochemistry and Fetal Nuchal Translucency Screening Study
Group. Am J Obstet Gynecol. 2005; 192(5): 13571361.

3. TENEA-COJAN TS, VIDRIGHIN CD, CIOBANU M, PAUN I et al. Breast-conserving surgery in breast cancer. Chirurgia. 2012; 107(5): 616-625.

4. BECKER R, SCHMITZ L, KILAVUZ S, STUMM M et al. 'Normal' nuchal translucency: a justification to refrain from detailed scan? Analysis of 6858 cases with special reference to ethical aspects. Prenat Diagn. 2012; 32(6): 550-556.

5. PATRU CL, ILIESCU DG, TANASE F, DRAGUSIN RC et al. Fetal Heart in the First Trimester. The Added Value of the Outflow Tracts Evaluation. Proceedings, Filodiritto Publisher. 2017; 87(4): 471-475.

6. VASILE I, MIREA C, VÎLCEA ID, PAŞALEGA M et al. Esophago-digestive anastomosis dehiscence. Chirurgia. 2009; 104(3): 281-286.

7. PERSICO N, MORATALLA J, LOMBARDI CM, ZIDERE $\mathrm{V}$ et al. Fetal echocardiography at 11-13 weeks by transabdominal high-frequency ultrasound. Ultrasound Obstet Gynecol. 2011; 37(3): 296-301.

8. RADU L, CARSOTE M, PREDESCU AM, TENEACOJAN TS et al. Biochemical parameters in patients using teriparatide. Rev. chim. (Bucharest). 2018; 69(12): 3483-3485.

9. FONG KW, TOI A, SALEM S, HORNBERGER LK et al. Detection of fetal structural abnormalities with US during early pregnancy. Radiographics. 2004; 24(1): 157-174.

10. HAAK MC, TWISK JW, VAN VUGT JM. How successful is fetal echocardiographic examination in the first trimester of pregnancy? Ultrasound Obstet Gynecol. 2002; 20(1): 9-13.

11. VÎLCEA ID, VASILE I, TOMESCU P, PASALEGA $M$ et al. Loco-regional advanced colorectal cancer: diagnostic and therapeutic features. Chirurgia. 2008; 103(2): 189-194.

12. LI Y, HUA Y, FANG J, WANG C et al. Performance of different scan protocols of fetal echocardiography in the diagnosis of fetal congenital heart disease: a systematic review and meta-analysis. PLoS One. 2013; 8(6): 64-84.

13. OGGÈ G, GAGLiOTI P, MACCANTI S, FAGGIANO $F$ et al. Prenatal screening for congenital heart disease with four-chamber and outflow-tract views: a multicenter study. Ultrasound Obstet Gynecol. 2006; 28(3): 779-84.

14. SMRCEK JM, BERG C, GEIPEL A, FIMMERS R et al. Detection rate of early fetal echocardiography and in utero development of congenital heart defects. J Ultrasound Med. 2006; 25(2): 187-196.

15. TENEA COJAN TS, RADU L, DAVITOIU DV, VLADU IM et al. The importance of the chemical composition of synthetic nets used in repair of parietal deffects. Rev. Chim. (Bucharest). 2018; 69(10): 2677-2681.

16. MULLER MA, CLUR SA, TIMMERMAN E, BILARDO CM. Nuchal translucency measurement and congenital heart defects: modest association in 
low-risk pregnancies. Prenat Diagn. 2007; 27(2): 164-169.

17. TENEA COJAN TS, MACOVEI A, PAUN I, COSTIN AI et al. Assessment of hormonal receptor immunoexpression and Her2 status in invasive breast cancer after conservative and radical surgery. Rom $J$ Morphol Embryol. 2018; 59(3): 763-772.

18. CLUR SA, OTTENKAMP J, BILARDO CM. The nuchal translucency and the fetal heart: a literature review. Prenat Diagn. 2009; 29(8): 739-748.

19. BELLOTTI M, FESSLOVA V, DE GASPERI C, ROGNONI $G$ et al. Reliability of the first-trimester cardiac scan by ultrasound-trained obstetricians with high-frequency transabdominal probes in fetuses with increased nuchal translucency. Ultrasound Obstet Gynecol. 2010; 36(3): 272.

20. MAKRYDIMAS G, SOTIRIADIS A, HUGGON IC, SIMPSON $\mathbf{J}$ et al. Nuchal translucency and fetal cardiac defects: a pooled analysis of major fetal echocardiography centers. Am J Obstet Gynecol. 2005; 192(1), 89-95.

21. BECKER R, WEGNER RD. Detailed screening for fetal anomalies and cardiac defects at the 11-13week scan. Ultrasound Obstet Gynecol. 2006; 27(6): 613-618.

22. ENE CG, MITROI M, VLADU IM, RADU L et al. Metabolic syndrome among patients with rheumatoid arthritis and the correlation with disease activity. Rev. Chim. (Bucharest). 2016; 70(6): 2108-2111.

23. SALTVEDT S, ALMSTRÖM H, KUBLICKAS M, VALENTIN L et al. Detection of malformations in chromosomally normal fetuses by routine ultrasound at 12 or 18 weeks of gestation-a randomised controlled trial in 39,572 pregnancies. BJOG. 2006; 113(6): 664-674.
24. NEDELCUTA R, POPESCU M, CALIN G. Digestive manifestations in Wilms' tumor. Proceedings of Neurogastro 2017 - Meeting of the Romanian Society of Neurogastroenterology with Rome IV Regional Central East European Meeting. 2017; 200.

25. NEDELCUTA R, BALEANU VD, CIORA C, CALIN $G$ et al. Possible retard in the language development to the children born through IVF (in vitro fertilisation). Rev. Chim. (Bucharest). 2019; 70(5): 1859-1862.

26. STANESCU GL, NEDELCUTA RM, DOP D, DIACONU $R$ et al. Brain abscess of unknown etiology in a 2 -year-old child: a case report. Rom $J$ Morphol Embryol. 2015; 56(3): 1201.

27. CLENCIU D, TENEA COJAN TS, DIJMARESCU AL, ENE CG et al. Diabetic Retinopathy in Relation with eGDR Value in Patients with Type 1 Diabetes Mellitus. Rev. Chim. (Bucharest). 2019; 70(4): 14341438.

28. NEDELCUTA RM, CALIN G, BALEANU VD, DAVITOIU DV et al. Anorexia, a first sign of diagnosis in severe pediatric disorders. Rev. Chim. (Bucharest). 2019; 70(5): 1698-1702.

29. GHEORMAN V, DINESCU VC, CRICIOTOIU O, STANCA D et al. Clinical and biochemical changes induced by alcohol at the patients with mental illness. Rev. Chim. (Bucharest). 2019; 70(4): 1406-1410.

30. CARVALHO JS, MOSCOSO G, TEKAY A, CAMPBELL $S$ et al. Clinical impact of first and early second trimester fetal echocardiography on high risk pregnancies. Heart. 2004; 90(8): 921-926.

31. RASIAH SV, PUBLICOVER M, EWER AK, KHAN KS et al. A systematic review of the accuracy of first-trimester ultrasound examination for detecting major congenital heart disease. Ultrasound Obstet Gynecol. 2006; 28(1): 110-116. 